\title{
TU/e EmonONEN

\section{A comparison between SSMF and large-Aeff Pure-Silica core fiber for Ultra Long-Haul 100G transmission}

\section{Citation for published version (APA):}

Sleiffer, V. A. J. M., Maalej, Z., Borne, van den, D., Kuschnerov, M., Veljanovski, V., Hirano, M., Yamamoto, Y., Sasaki, T., Jansen, S. L., Napoli, A., \& Waardt, de, H. (2011). A comparison between SSMF and large-Aeff Pure-Silica core fiber for Ultra Long-Haul 100G transmission. Optics Express, 19(26), B710-B715. https://doi.org/10.1364/OE.19.00B710

DOI:

10.1364/OE.19.00B710

Document status and date:

Published: 01/01/2011

\section{Document Version:}

Publisher's PDF, also known as Version of Record (includes final page, issue and volume numbers)

\section{Please check the document version of this publication:}

- A submitted manuscript is the version of the article upon submission and before peer-review. There can be important differences between the submitted version and the official published version of record. People interested in the research are advised to contact the author for the final version of the publication, or visit the $\mathrm{DOI}$ to the publisher's website.

- The final author version and the galley proof are versions of the publication after peer review.

- The final published version features the final layout of the paper including the volume, issue and page numbers.

Link to publication

\section{General rights}

Copyright and moral rights for the publications made accessible in the public portal are retained by the authors and/or other copyright owners and it is a condition of accessing publications that users recognise and abide by the legal requirements associated with these rights.

- Users may download and print one copy of any publication from the public portal for the purpose of private study or research.

- You may not further distribute the material or use it for any profit-making activity or commercial gain

- You may freely distribute the URL identifying the publication in the public portal.

If the publication is distributed under the terms of Article 25fa of the Dutch Copyright Act, indicated by the "Taverne" license above, please follow below link for the End User Agreement:

www.tue.nl/taverne

Take down policy

If you believe that this document breaches copyright please contact us at:

openaccess@tue.nl

providing details and we will investigate your claim. 


\title{
A comparison between SSMF and large- $A_{\text {eff }}$ Pure-Silica core fiber for Ultra Long-Haul 100G transmission
}

\author{
V.A.J.M. Sleiffer, ${ }^{1,{ }^{*}}$ Z. Maalej, ${ }^{2}$ D. van den Borne, ${ }^{3}$ M. Kuschnerov,${ }^{3}$ V. Veljanovski, ${ }^{3}$ M. \\ Hirano, ${ }^{4}$ Y. Yamamoto, ${ }^{4}$ T. Sasaki, ${ }^{4}$ S.L. Jansen, ${ }^{3}$ A. Napoli, ${ }^{3}$ and H. de Waardt ${ }^{1}$ \\ ${ }^{1}$ COBRA institute, Eindhoven University of Technology, Den Dolech 2, 5612 AZ Eindhoven, The Netherlands \\ ${ }^{2}$ Munich University of Technology, Arciss Strasse 21, 80333 Munich, Germany \\ ${ }^{3}$ Nokia Siemens Networks, St. Martin Strasse 76, 81541 Munich, Germany \\ ${ }^{4}$ Sumitomo Electric Industries, Ltd., 1, Taya-cho, Sakae-ku,Yokohama, 244-8588, Japan \\ v.a.j.m.sleiffer@tue.nl
}

\begin{abstract}
We compare the transmission performance of $112-\mathrm{Gb} / \mathrm{s}$ POLMUX-QPSK modulation over large- $A_{\text {eff }}$ Pure-Silica core fiber and SSMF using EDFA-only amplification. The higher nonlinear threshold of the large- $A_{\text {eff }}$ Pure-Silica core fiber allows for a 55\% increase in transmission distance. By using back-propagation an additional $10 \%$ increase is observed. In case spans with equal length for both fiber types and two splices per span only would have been used, resulting in a lower span loss for the large- $\mathrm{A}_{\mathrm{eff}}$ Pure-Silica core fiber, the total increase grows to $85 \%$.
\end{abstract}

(C)2011 Optical Society of America

OCIS codes: (060.2360) Fiber optics links and subsystems; (060.2400) Fiber properties; (060.4510) Optical communications.

\section{References and links}

1. V. Veljanovski, V. Sleiffer, D. van den Borne, J. Capasso, H. Kuluslu, J. Seixas, V. Schramm, A. Tschersich, R. Nogueira, N. Pavlovic, K. Ivarson, S. Spaelter, and H. de Waardt, "125 Gb/s CP-QPSK Field Trial over 4108 km of Installed Submarine Cable," in Optical Fiber Communication Conference, OSA Technical Digest (CD) (Optical Society of America, 2011), paper PDPD3. http://www.opticsinfobase.org.janus.libr.tue.nl/abstract.cfm?URI=OFC-2011-PDPD3

2. D. van den Borne, V. Sleiffer, M. S. Alfiad, S. L. Jansen, and T. Wuth, "Polmux-QPSK modulation and coherent detection: The challenge of long-haul 100G transmission," in European Conference on Optical Communication, Paper 3.4.1 (2009).

3. G. Charlet, M. Salsi, P. Tran, M. Bertolini, H. Mardoyan, J. Renaudier, O. Bertran-Pardo, and S. Bigo, "72x100Gb/s Transmission over Transoceanic Distance, Using Large Effective Area Fiber, Hybrid RamanErbium Amplification and Coherent Detection," in Optical Fiber Communication Conference, OSA Technical Digest (CD) (Optical Society of America, 2009), paper PDPB6. http://www.opticsinfobase.org/abstract.cfm? URI=OFC-2009-PDPB6

4. M. Salsi, C. Koebele, P. Tran, H. Mardoyan, S. Bigo, and G. Charlet, "80x100-Gbit/s transmission over 9,000km using erbium-doped fibre repeaters only," in European Conference on Optical Communication, We.7.C.3 (2010).

5. J. Cai, Y. Cai, C. Davidson, D. Foursa, A. Lucero, O. Sinkin, W. Patterson, A. Pilipetskii, G. Mohs, and N. Bergano, "Transmission of 96x100G Pre-Filtered PDM-RZ-QPSK Channels with 300\% Spectral Efficiency over $10,608 \mathrm{~km}$ and $400 \%$ Spectral Efficiency over 4,368km," in Optical Fiber Communication Conference, OSA Technical Digest (CD) (Optical Society of America, 2010), paper PDPB10. http://www.opticsinfobase.org/abstract.cfm? URI=OFC-2010-PDPB10

6. Y. Yamamoto, M. Hirano, and T. Sasaki, "A New Class of Optical Fiber to Support Large Capacity Transmission," in Optical Fiber Communication Conference, OSA Technical Digest (CD) (Optical Society of America, 2011), paper OWA6. http://www.opticsinfobase.org/abstract.cfm? URI=OFC-2011-OWA6

7. M. S. Alfiad, D. van den Borne, T. Wuth, M. Kuschnerov, and H. de Waardt, "On the Tolerance of 111-Gb/s POLMUX-RZ-DQPSK to Nonlinear Transmission Effects," J. Lighwave Technol. 29(2), 162-170 (2011).

8. D. Marcuse, "Loss Analysis of Single-Mode Fiber Splices," Bell Syst. Tech. J. 56, 703-718 (1977).

9. M. S. Alfiad, D. van den Borne, S. L. Jansen, T. Wuth, M. Kuschnerov, G. Grosso, A. Napoli, and H. de Waardt, "A Comparison of Electrical and Optical Dispersion Compensation for 111-Gb/s POLMUX-RZ-DQPSK," J. Lighwave Technol. 27(16), 3590-3598 (2009).

10. V. Curri, P. Poggiolini, G. Bosco, A. Carena, and F. Forghieri, "Performance Evaluation of Long-Haul $111 \mathrm{~Gb} / \mathrm{s}$ PM-QPSK Transmission Over Different Fiber Types," Photonics Technology Letters 22(19), 1446-1448 (2010). 
11. D. S. Millar, S. Makovejs, C. Behrens, S. Hellerbrand, R. I. Killey, P. Bayvel, and S. J. Savory, "Mitigation of fibre nonlinearity using a digital coherent receiver," IEEE J. Sel. Top. Quant. Electron. 16(5), 1217-1226 (2010).

12. E. Ip and J. M. Kahn, "Compensation of dispersion and nonlinear impairments using digital backpropagation," J. Lighwave Technol. 26(20), 3416-3425 (2008).

13. F. Yaman and G. Li, "Nonlinear impairment compensation for polarization-division multiplexed WDM transmission using digital backward propagation," IEEE Photon. J. 1(2), 144-152 (2009).

14. L. Li, Z. Tao, L. Dou, W. Yan, S. Oda, T. Tanimura, T. Hoshida, and J. C. Rasmussen, "Implementation Efficient Nonlinear Equalizer Based on Correlated Digital Backpropagation," in Optical Fiber Communication Conference, OSA Technical Digest (CD) (Optical Society of America, 2011), paper OWW3. http://www.opticsinfobase.org.janus.libr.tue.nl/abstract.cfm? URI=OFC-2011-OWW3

15. Z. Maalej, V. Sleiffer, A. Napoli, M. Kuschnerov, B. Spinnler, and N. Hanik, "Reduced complexity for backpropagation method algorithm," IEEE Phot. Conf., to be published (2011).

\section{Introduction}

The rapid increase in popularity of very bandwidth-intensive applications such as internet video, cloud storage and social networking requires large volumes of data to be transmitted over long distances. This has fuelled the historically exponential growth of data traffic volumes in the worldwide telecommunication network, and based on current trends it is likely to continue to drive an unsurpassed need for transmission capacity over the next decade. This requires ultra long-haul $100 \mathrm{G}$ transport solutions for both the core network and submarine deployment [1].

Polarization-multiplexed quadrature phase shift keying (POLMUX-QPSK) [2] has emerged in recent years as the most suitable modulation format for $100 \mathrm{G}$ line rates, as it is compatible with the standardized $50-\mathrm{GHz}$ channel spacing. This allows for a spectral efficiency of $2.0 \mathrm{~b} / \mathrm{s} / \mathrm{Hz}$, scaling C-band only transmission systems to a total capacity of up to $10 \mathrm{~Tb} / \mathrm{s}$. Recent experiments using 100G POLMUX-QPSK modulation have demonstrated the feasibility of unregenerated transmission over ultra long-haul transmission distances [3-5]. A key enabler of the demonstrated ultra long-haul transmission distances is on one hand Raman amplification schemes or on the other hand the use of very short span lengths. For greenfield deployments, an alternative approach might be the deployment of fiber types specifically optimized for dispersion unmanaged 100G transmission which guarantees both a lower span loss as well as a strongly increased nonlinear threshold [6, 7].

In this paper we show ultra long-haul transmission using 100G POLMUX-QPSK modulation for a transmission system consisting of EDFA-only amplification and standard 80-km span lengths. The ultra long-haul transmission reach in this experiment is enabled by the use of large- $A_{\text {eff }}$ Pure-Silica core fiber (LA-PSCF). We discuss as well a comparison between the LA-PSCF and standard single-mode fiber (SSMF) and show that the improved nonlinear coefficient and higher dispersion coefficient of LA-PSCF allow for a $55 \%$ increase and by using back-propagation (BP) a 65\% increase in transmission distance. For the experimental comparison the span lengths for both fiber types were different and formed by combining multiple spools together, yielding additional losses per span. In case the span lengths would have been the same and would have only two splices per span, an additional $\sim 20 \%$ in reach improvement due to the lower span loss of the LA-PSCF is expected. This would result in a total increase in transmission distance of $85 \%$ by using LA-PSCF instead of SSMF.

\#155624 - \$15.00 USD Received 30 Sep 2011; revised 23 Nov 2011; accepted 25 Nov 2011; published 5 Dec 2011

(C) 2011 OSA

12 December 2011 / Vol. 19, No. 26 / OPTICS EXPRESS B711 

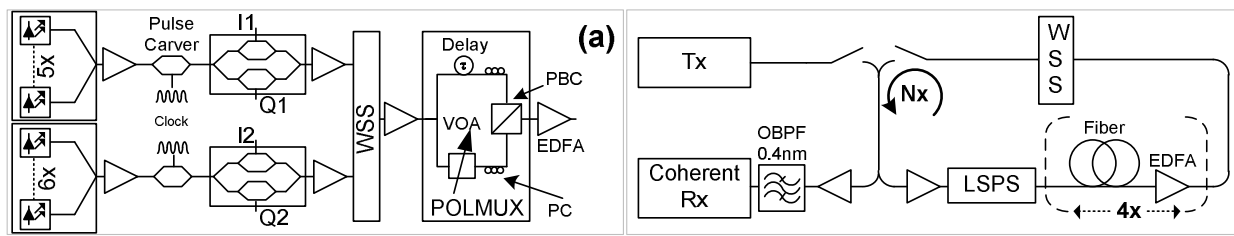

(b)

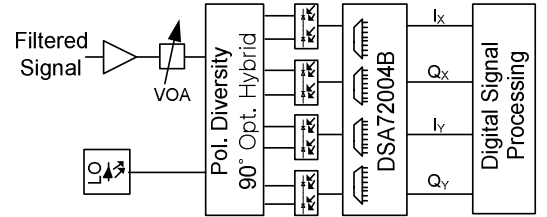

(c)
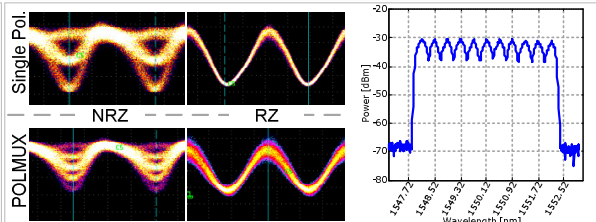

(d)

Fig. 1. Experimental setup. (a) Transmitter (Tx), (b) Re-circulating loop setup, (c) Polarizationdiversity coherent receiver (Rx), (d) Optical eyes and spectrum. WSS: Wavelength Selective Switch, LSPS: Loop-Synchronized Polarization Scrambler.

\section{Experimental setup}

The experimental setup used is depicted in Fig. 1. At the transmitter (Fig. 1(a)), two laser combs are generated by coupling together 5 lasers on the ITU-grid and 6 lasers on the ITUoffset grid by using a passive coupler. The two combs consist of a mix of ECL and DFB lasers, where the center channel is an ECL laser with a 100-kHz linewidth. The output signals of both combs are first return-to-zero (RZ) pulse-carved by means of a Mach-Zehnder Modulator (MZM) driven by a $28-\mathrm{GHz}$ clock signal. Subsequently the signals are $56-\mathrm{Gb} / \mathrm{s}$ QPSK modulated with an IQ-modulator. Two outputs of a pulse-pattern generator (PPG), generating $2^{15}$ PRBS sequences at a 28-Gbaud symbol rate, are first cleaned up using two D flip-flops (DFF). One of the two DFF outputs is first delayed by 52 symbols for de-correlation and both are after amplification fed to the IQ-modulators. The 56-Gb/s RZ-QPSK modulated signals are first amplified and subsequently multiplexed using a wavelength selective switch (WSS, Waveshaper 4000S) on a 50-GHz ITU-grid. After the multiplexing stage the signal is fed into a polarization-multiplexing (POLMUX) stage. Here the incoming optical signal is split up into two equally powered tributaries, one delayed by 230 symbols for de-correlation, and subsequently re-combined using a polarization beam combiner (PBC), resulting in an 112-Gb/s POLMUX-RZ-QPSK modulated signal. The resulting optical spectrum containing eleven 112-Gb/s POLMUX-RZ-QPSK modulated signals is shown in Fig. 1(d).

Table 1. Average Fiber Parameters

\begin{tabular}{|l|r|r|}
\cline { 2 - 3 } \multicolumn{1}{c|}{} & \multicolumn{1}{c|}{ SSMF } & LA-PSCF \\
\hline Attenuation $[\mathrm{dB} / \mathrm{km}]$ & 0.19 & 0.161 \\
\hline Span Length $[\mathrm{km}]$ & 75 & 82 \\
\hline Span Loss (with splices) $[\mathrm{dB} / \mathrm{km}]$ & 14.6 & 14.8 \\
\hline Chromatic Dispersion @ $1550 \mathrm{~nm}[\mathrm{ps} / \mathrm{nm} / \mathrm{km}]$ & 16.8 & 21.0 \\
\hline Dispersion slope $\left[\mathrm{ps} / \mathrm{nm}^{2} / \mathrm{km}\right]$ & 0.057 & 0.061 \\
\hline Effective Core Area $\left[\mu \mathrm{m}^{2}\right]$ & 80 & 133 \\
\hline Nonlinear coefficient $\left[\mathrm{W}^{-1} \cdot \mathrm{km}^{-1}\right]$ & 1.3 & 0.6 \\
\hline
\end{tabular}

The transmission link consists of a re-circulating loop (Fig. 1(b)) containing a LoopSynchronized Polarization Scrambler (LSPS), four fiber spans followed by an EDFA to compensate the losses, and a wavelength selective switch (WSS). The LSPS is used to emulate the polarization changes occurring in a long-haul transmission link. The WSS emulates optical add-drop nodes and equalizes the optical spectrum. The four fiber spans are either SSMF or large- $\mathrm{A}_{\text {eff }}$ Pure-Silica core fiber. The specifications of both fibers are given in Table 1. It can be observed that the average span loss is approximately the same for both fiber 
types, whereas one would expect a lower span loss for large- $\mathrm{A}_{\mathrm{eff}}$ Pure-Silica core fiber due the lower attenuation. The SSMF span loss follows from the attenuation coefficient plus splice losses $(75 \mathrm{~km} \times 0.19 \mathrm{~dB} / \mathrm{km}+3 \times 0.1 \mathrm{~dB})$. The span length of the LA-PSCF is $82 \mathrm{~km}$ instead of $75 \mathrm{~km}$ for SSMF, but in addition the span loss of the LA-PSCF is $1.6 \mathrm{~dB}$ higher as expected from the attenuation coefficient times span length. This additional span loss results from the splice losses between the LA-PSCF to SSMF pigtails. The difference in core area of the LA-PSCF and SSMF results in a $\sim 0.3 \mathrm{~dB}$ higher splicing loss compared to splicing two SSMFs together [8], yielding a $0.4 \mathrm{~dB}$ loss per splice. The 82-km LA-PSCF span consists of two spools with both two splices to SSMF, resulting in a total span loss of $14.8 \mathrm{~dB}(82 \mathrm{~km} \mathrm{x}$ $0.161 \mathrm{~dB} / \mathrm{km}+4 \times 0.4 \mathrm{~dB})$. Please note that due to the longer span length, the total transmission distance for each loop re-circulation is $300 \mathrm{~km}$ in case of SSMF compared to 328 $\mathrm{km}$ for the LA-PSCF.

After transmission, the center channel at $1550.12 \mathrm{~nm}$ is filtered out using a demultiplexing filter with a 50-GHz bandwidth and subsequently fed to a polarization-diversity 90) optical hybrid (Fig. 1(c)). The signal is mixed with a local oscillator (LO) with $100-\mathrm{kHz}$ linewidth, tuned within $+/-200 \mathrm{MHz}$ of the center wavelength. The 8 outputs of the 90) optical hybrid are converted to the electrical domain using balanced photodiodes, and subsequently digitized using a 50-Gsamples/s real-time digital sampling scope (DSA72004B). Two million samples, corresponding to 4.48 million bits are used for offline digital signal processing. Per measurement point, four shots are taken at different time instances from which the average BER is presented in the results section. Offline digital signal processing is used to demodulate the resulting samples as described in [9].
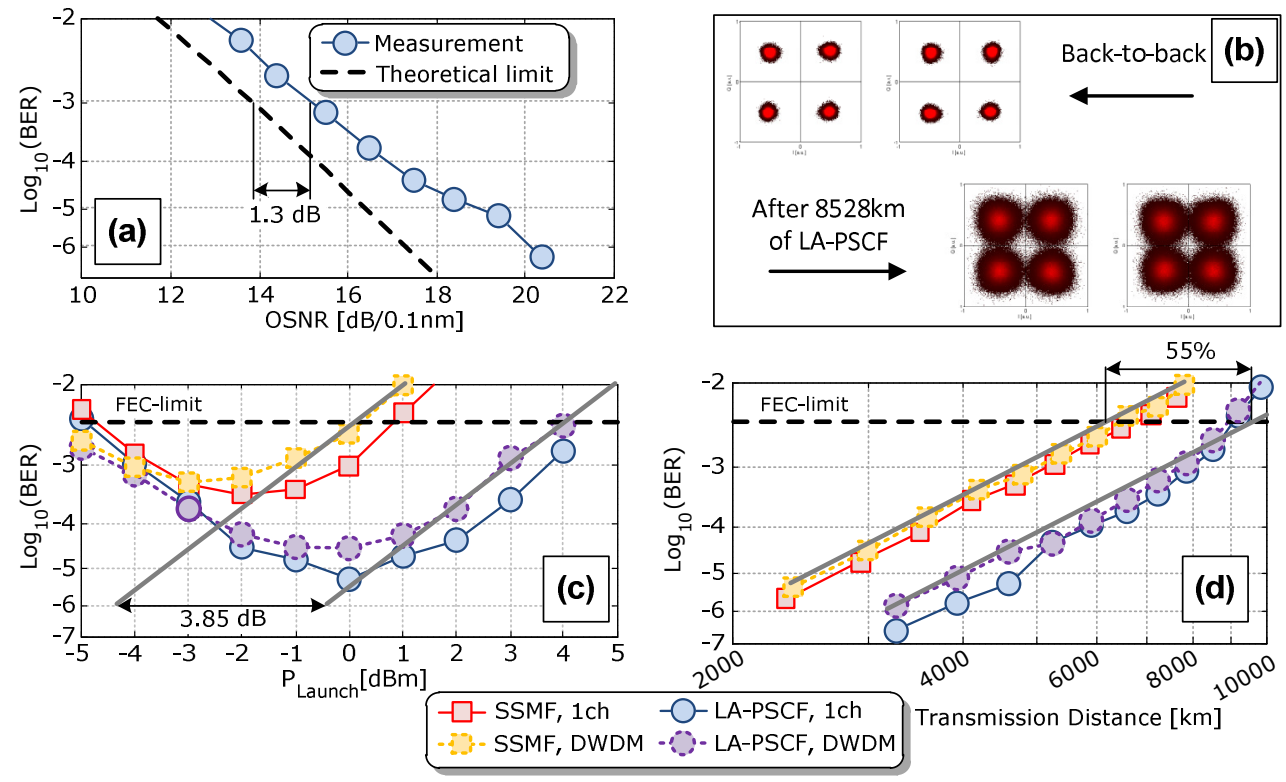

Fig. 2. (a) Back-to-back curves: Theoretical limit and measured curve, (b) Recovered Constellations, (c) $\log _{10}$ (BER) versus launch power per channel after $\sim 4500 \mathrm{~km}$ of transmission distance, (d) $\log _{10}$ (BER) versus transmission distance

\section{Transmission results}

Figure 2(a) shows the measured back-to-back curve of the 112-Gb/s POLMUX-RZ-DQPSK channel. The required OSNR to reach a BER of $10^{-3}$ is $15.2 \mathrm{~dB} / 0.1 \mathrm{~nm}$, which corresponds to $\mathrm{a} \sim 1.3 \mathrm{~dB}$ penalty with respect to theory. The recovered constellation of the signal that is transmitted is shown in Fig. 2(b). In Fig. 2(c) the $\log _{10}(B E R)$ is depicted as a function of the launch power per channel after a transmission distance of $\sim 4500 \mathrm{~km}$. Please note that, as the span lengths for both fiber types are not equal, the number of loops is 15 for SSMF spans and

\#155624 - \$15.00 USD Received 30 Sep 2011; revised 23 Nov 2011; accepted 25 Nov 2011; published 5 Dec 2011 (C) 2011 OSA

12 December 2011 / Vol. 19, No. 26 / OPTICS EXPRESS B713 
14 for LA-PSCF spans. This means we obtain almost the same received OSNRs, because the average span loss for LA-PSCF is slightly higher than for SSMF, but the additional loop for SSMF spans adds approximately the same OSNR degradation. This can also be observed in Fig. 2(c) from the overlapping curves in the OSNR limited region.

As the received OSNR is near to identical for both fiber types the difference in transmission performance is resulting solely from the difference in the nonlinear threshold. The total improvement in nonlinear threshold is $\sim 3.85 \mathrm{~dB}$ between LA-PSCF and SSMF, as can be observed in Fig. 2(c). The larger core size of LA-PSCF (and the reduced refractive index) results in a nonlinear coefficient of $0.6 \mathrm{~W}^{-1} \cdot \mathrm{km}^{-1}$, which is $3.4 \mathrm{~dB}$ lower than for SSMF $\left(1.3 \mathrm{~W}^{-1} \cdot \mathrm{km}^{-1}\right)$. The higher dispersion coefficient of LA-PSCF $(21.0 \mathrm{ps} / \mathrm{nm} / \mathrm{km})$ compared to SSMF $(16.8 \mathrm{ps} / \mathrm{nm} / \mathrm{km})$ results as well in an increase of the nonlinear threshold. In [10] it has been shown that the nonlinear tolerance scales approximately linearly with the difference in dispersion coefficient to the power of 0.4 , which amounts to a difference of + $0.4 \mathrm{~dB}\left(10 \cdot \log _{10}\left((21 / 16.8)^{0.4}\right)\right)$. The longer effective length of LA-PSCF reduces the nonlinear threshold somewhat $(-0.7 \mathrm{~dB})$, but this is partially offset by the larger splice loss between LA-PSCF and SSMF pigtail $(+0.3 \mathrm{~dB})$. The additional loop for SSMF adds $\mathrm{a}+0.3 \mathrm{~dB}$ penalty, and the total improvement in nonlinear threshold relative to SSMF amounts therefore to $3.7 \mathrm{~dB}$, which is close to the measured $3.85 \mathrm{~dB}$ difference.

Figure $2(d)$ shows the transmission distance as a function of the measured $\log _{10}(B E R)$. It can be observed that for SSMF the FEC-limit (BER of $3.8 \cdot 10^{-3}$ ) is reached after $6100 \mathrm{~km}$ of transmission, whereas the $\sim 3.85 \mathrm{~dB}$ increase in nonlinear threshold for the LA-PSCF results in an increase of this distance to $9500 \mathrm{~km}$. This is a $55 \%$ increase in transmission distance resulting from the lower nonlinear coefficient of the LA-PSCF. Note that for $80-\mathrm{km}$ spans with optimum span loss, i.e. $80 \mathrm{~km}$ of fiber and two splices only, the difference is an additional $1.5 \mathrm{~dB}$ between LA-PSCF and SSMF (factoring in the $2 \times 0.3 \mathrm{~dB}$ higher splice loss between the LA-PSCF and SSMF pigtails). This would add an approximate $20 \%$ difference in reach improvement between both fibers because of the lower attenuation of the LA-PSCF, resulting in a total difference in maximum feasible transmission distance of $75 \%$.

\section{Back-propagation}

An even larger improvement in transmission distance can be obtained by applying nonlinear compensation techniques. Back-propagation (BP) [11-13] recently gained a momentum being one of the most suitable techniques since it compensates bulk chromatic dispersion (CD), selfphase modulation (SPM) and, to some extent, cross-phase modulation (XPM) at the same time.

The BP algorithm is based on the solution of the Nonlinear Schrödinger Equation (NLSE) and serves as an approximate inverse channel model. The NLSE is a precise approximation of optical fiber propagation for the case of a single polarization optical field. However, in modern WDM long-haul systems two polarizations are employed to increase the spectral efficiency. Therefore the so-called vectored NLSE has to be used to cope with polarization effects on the nonlinear interactions as described in [13]. Moreover optical transmission fibers are nominally not birefringent, however they still exhibit residual birefringence that randomly scatters the polarization of the electrical field. By averaging the vectored NLSE over these relative fast polarizations changes, it results in a new version of NLSE, the so-called Manakov Equations [13], which is used in the BP algorithm.

To apply BP, the full knowledge of the link is required. The span lengths, the dispersion map, the fiber type, and the launch power have to be known by the receiver. So far, BP has been mainly discussed at an academic level without clear proposal for real-time hardware implementation. However, recent research showed that the computational requirements can be decreased considerably. In [14], it was shown that the number of required steps per span can be reduced by using the correlated BP. In [15], a complexity reduction of $50 \%$ without considerable system performance degradation is shown.

\#155624 - \$15.00 USD Received 30 Sep 2011; revised 23 Nov 2011; accepted 25 Nov 2011; published 5 Dec 2011

(C) 2011 OSA

12 December 2011 / Vol. 19, No. 26 / OPTICS EXPRESS B714 


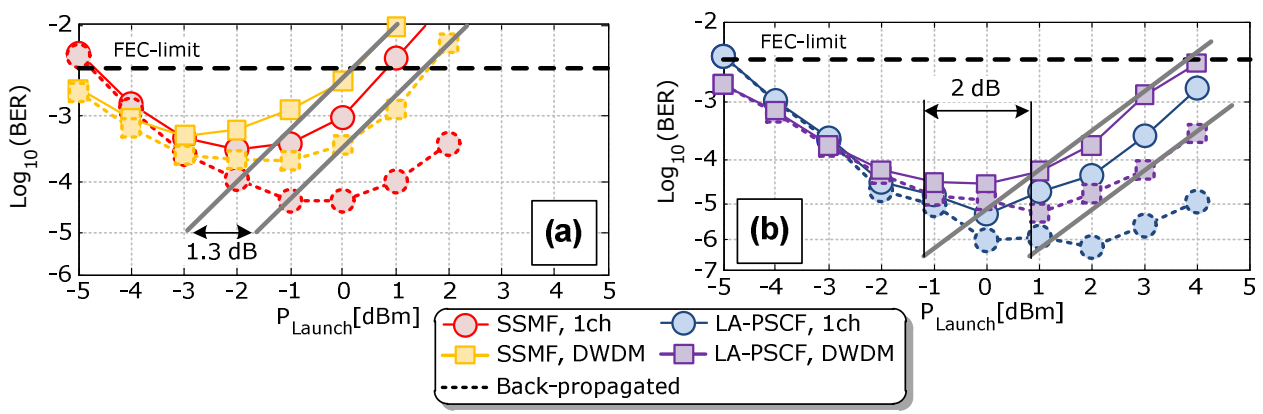

Fig. 3. $\log _{10}(\mathrm{BER})$ versus launch power per channel after $\sim 4500 \mathrm{~km}$ of transmission distance for (a) SSMF, and (b) LA-PSCF as fiber type.

In Fig. 3(a) (SSMF) and (b) (LA-PSCF) the same results as in Fig. 2(c) are shown, with additionally the results after applying BP. The BP method used considers one single step per span. The results show that with $\mathrm{BP}$, an improvement in nonlinear threshold of $\sim 2 \mathrm{~dB}$ for single channel transmission and $\sim 1.3 \mathrm{~dB}$ for WDM transmission over SSMF is obtained. For transmission over LA-PSCF, a nonlinear threshold improvement of $\sim 3 \mathrm{~dB}$ for single channel transmission is obtained. For WDM transmission, the nonlinear threshold improvement is $\sim 2$ dB.

Figure 4 show the $\log _{10}(\mathrm{BER})$ results as a function of the transmission distance for the WDM transmission over LA-PSCF and SSMF. For SSMF the transmission distance has improved by $16 \%$ at the FEC-limit. For LA-PSCF, the improvement is about $26 \%$. This means an additional 10\% difference in reach improvement between the fibers, in favor of LAPSCF. This brings the total measured reach improvement when employing LA-PSCF instead of SSMF to 65\%. In case spans with equal length and two splices per span would have been used, resulting in a lower span loss for the LA-PSCF, the increase in reach sums up to be $85 \%$.

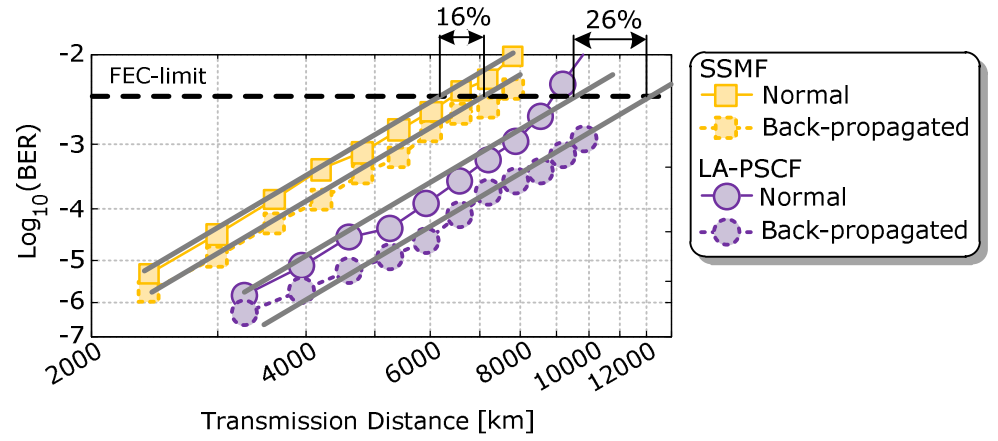

Fig. 4. $\log _{10}(\mathrm{BER})$ versus transmission distance for WDM transmission

\section{Conclusion}

In this paper we have shown a comparison of two fiber types, SSMF and large- $\mathrm{A}_{\text {eff }}$ PureSilica Core fiber (LA-PSCF) for ultra long-haul 112-Gb/s POLMUX-RZ-DQPSK transmission on a $50-\mathrm{GHz}$ grid. We have shown that the increased core size and higher dispersion coefficient of the LA-PSCF allows for a $3.85 \mathrm{~dB}$ increase in nonlinear threshold, which translates into an increase in feasible transmission distance of 55\%. An additional reach improvement when using BP of 10\% in favor of LA-PSCF has been shown. In case spans with equal length and two splices per span would have been used to reduce the span loss, this would result in a total increase of feasible transmission distance of $85 \%$ by using LA-PSCF instead of SSMF.

\#155624 - \$15.00 USD Received 30 Sep 2011; revised 23 Nov 2011; accepted 25 Nov 2011; published 5 Dec 2011

(C) 2011 OSA

12 December 2011 / Vol. 19, No. 26 / OPTICS EXPRESS B715 